\title{
Unusual pathways-From frustration to fascination
}

\author{
Promila Verma*, Rakesh Yadav, Anil Chandra, Aseem Prakash Tikku \\ Chhatrapati Shahuji Maharaj Medical University, Lucknow, India \\ Email: "promilarajesh@yahoo.co.in, rakeshanita10@yahoo.in, ahanachandra@yahoo.com, crown_tikku@yahoo.com
}

Received 17 March 2012; revised 10 April 2012; accepted 21 April 2012

\begin{abstract}
The main objectives of root canal treatment are thorough shaping and cleaning of all pulp spaces and its complete obturation with an inert filling material. The presence of untreated canal may be a reason for failure of endodontic therapy. To achieve satisfactory root canal therapy, a proper and in-depth knowledge of complex and abnormal root canal morphology is essential.
\end{abstract}

Keywords: Root Canal Anatomy; Mandibular Molar; Multiple Canals

\section{INTRODUCTION}

There are situations which are encountered during endodontic treatment when we stumble upon a unique case with an extra root, extra palatal canal, extra distobuccal root, or canal located at other than normal location. Sometimes endodontic failure occurs due to incomplete canal obturation and the presence of untreated canals. Thus the sound knowledge of the root canal and pulp chamber anatomy is a pre-requisite for successful root canal treatment [1]. Many of the challenges faced during root canal treatment may be directly attributed to an inadequate understanding of the tooth morphology. Anatomic variation in the number of roots and root canal can occur in any tooth.

Taurodontism is caused by the failure of Hertwig's epithelial sheath diaphragm to invaginate at the proper horizontal level [2]. Frequently molars are affected by taurodontism. Premolars present a lower incidence and the mandibular premolars are commonly affected. This case report presents a bilateral case of radix entomolaris and unusual root canal anatomy of bilateral second mandibular premolars with Taurodontism.

\section{CASE REPORT}

A 35 year Indian male with non contributory medical history reported to the department of conservative den-

"Corresponding author. tistry and endodontic with pain in left and right lower posterior jaw. Clinical examination revealed carious exposed lower left and right mandibular second premolar and molar. His orthopentomograph X-ray revealed normal periodontal ligament widening of both the first molar and second premolar (Figure 1). An I.O.P.A X-ray was also advised which revealed an extra root in the \#36 and \#35 with single root but with two root canal (Figure 2). His right lower quadrant also exhibited extra root in first molar and atypical root canal anatomy in lower second premolar (Figure 3). Both the premolars also exhibited large pulp chamber and elongated with much greater apico occlusal height. A dentascan was advised for careful examination of the extra root canal orifice and canal (Figure 4).

Firstly the lower left quadrant was initiated. The teeth were anesthetized and isolated with a rubber dam. Endo $\mathrm{Z}$ bur was used to gain access to the pulp chamber. After an adequate access preparation, two mesial and two distal canals orifice were found in left mandibular first molar. The second premolar exhibited wide pulp chamber with two separate canals. The canals were initially negotiated with \#10 K flex file. First molar had four access opening and four root canals (Figure 5). There was difficulty in assessing the canals in the \#35 as the canals were apicaly placed.

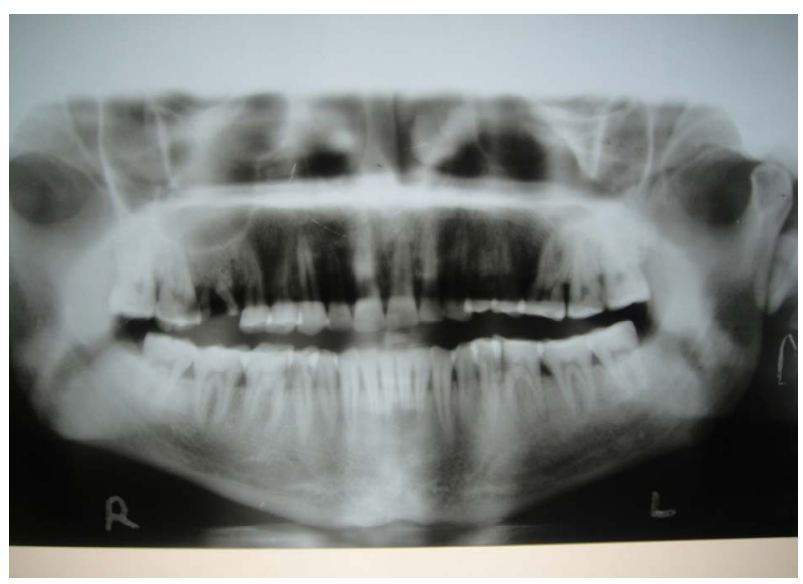

Figure 1. OPG. 


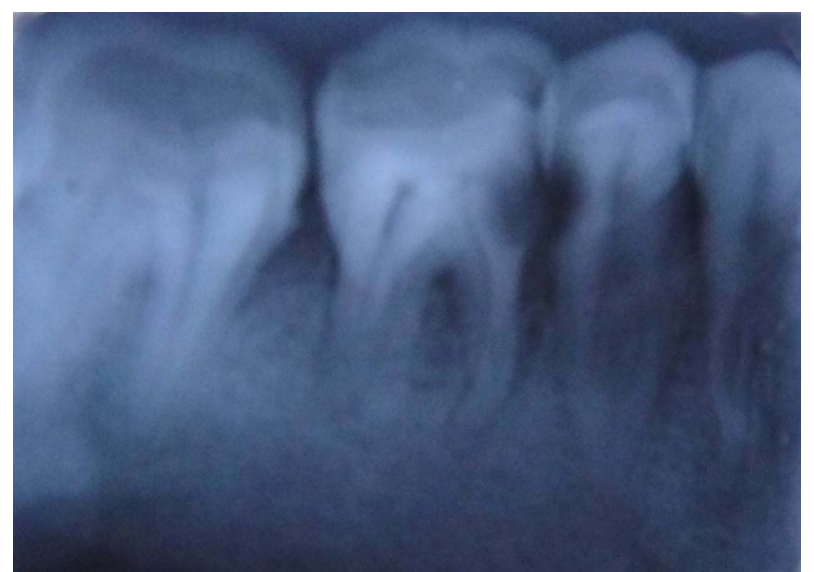

Figure 2. I.O.P.A. X-ray which shows an extra root in the \#36 and \#35 with single root but with two root canal.

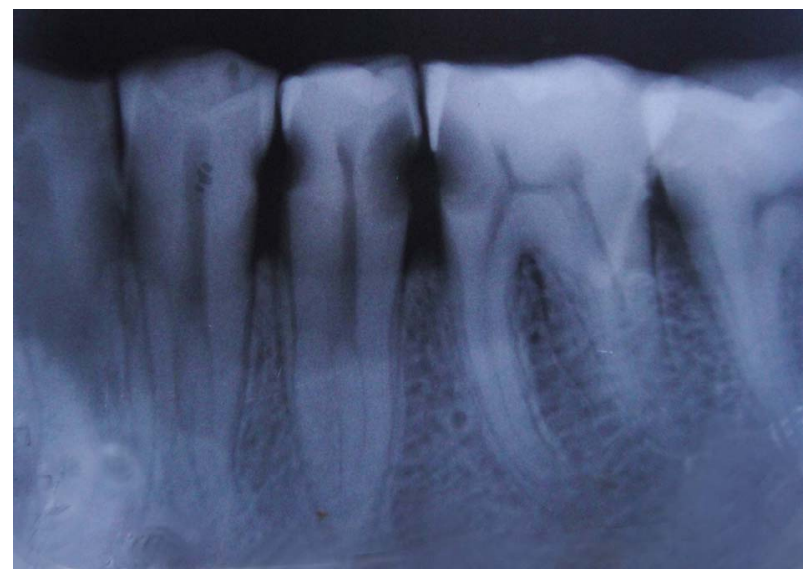

Figure 3. Atypical root canal anatomy of \#45 and extra root in \#46.

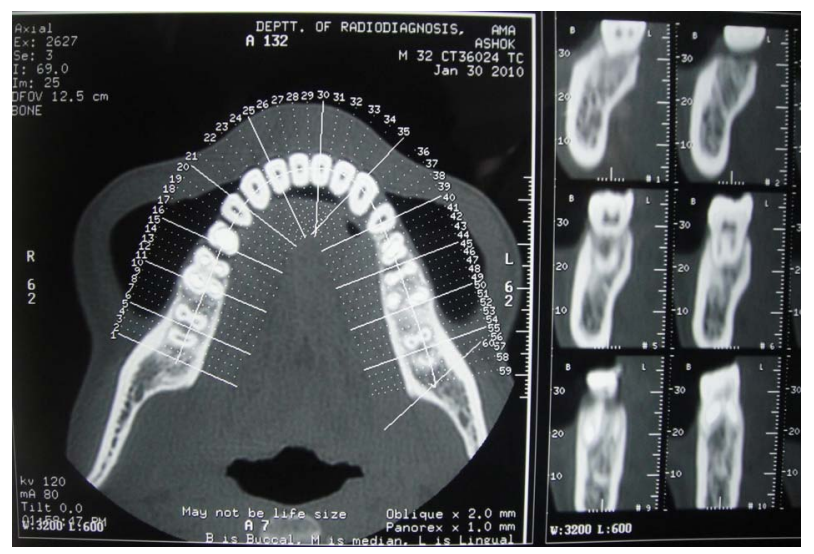

Figure 4. Dentascan.

Right II mandibular premolar exhibited three root canal orifices, four separate root canal (Figure 6). Operating Microscope was used to explore the pulp chamber in order to find orifices. To gain sufficient access into the canal of mandibular right second premolar access opening was extended mesially. Orifice location was not easy

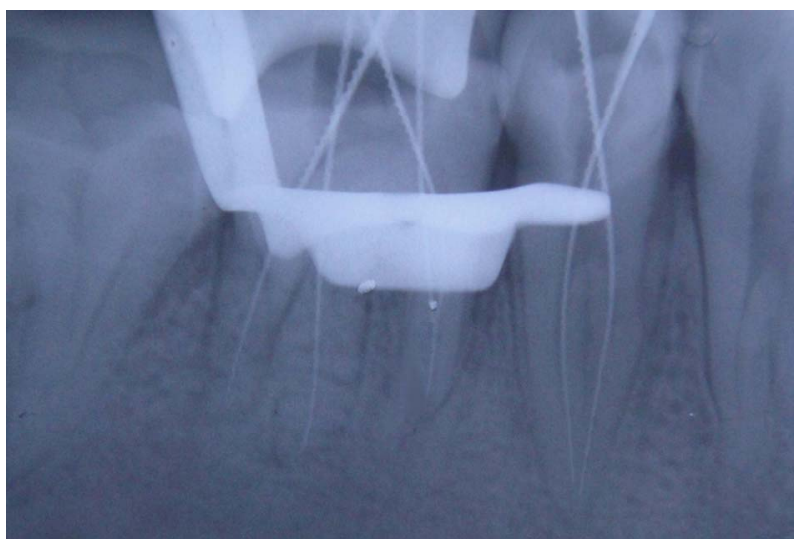

Figure 5. Four access opening and four root canals had been derivated from First molar.

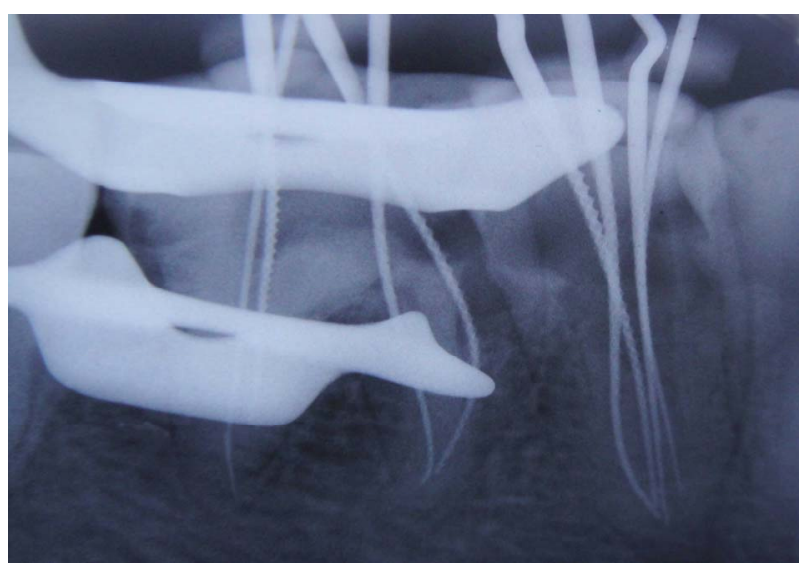

Figure 6. Four separate root canal.

as pulp chamber was unusually long. After careful inspection one mesiobuccal, one distobuccal and two mesial canals was located in the right mandibular second premolar. All the canals were instrumented up to $25 \mathrm{~K}$ flex file under copious irrigation with $2.5 \%$ sodium hypochlorite during instrumentation. Two weeks later, after drying the canals with paper point obturation was done using gutta flow and lateral condensation (Figures $\mathbf{7}$ and $\mathbf{8}$ ). Later the access cavity was sealed with silver amalgam.

\section{DISCUSSION}

Consistently high level of success in endodontic treatment requires an understanding of root canal anatomy and morphology [3]. The clinician must have a thorough understanding of normal anatomy and must be prepared to identify those teeth that exhibit unusual anatomical configuration. Based on literature, it is evident that knowledge of the anatomical variations of the mandibular molar and second premolar is extremely important for success of endodontic treatment. Mandibular first molar usually has two roots (mesial \& distal), but occasionally three, with a supernumery distolingual root. The root 


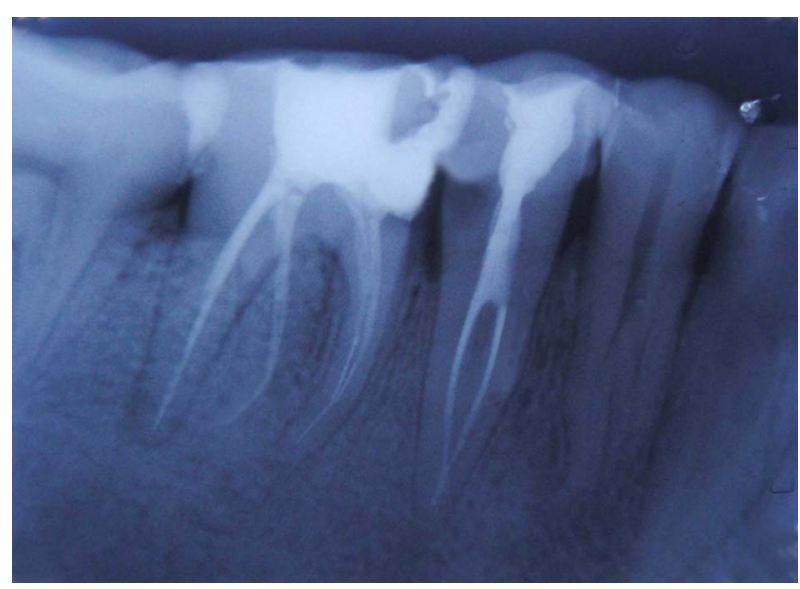

Figure 7. Obturated canal with guttaflow.

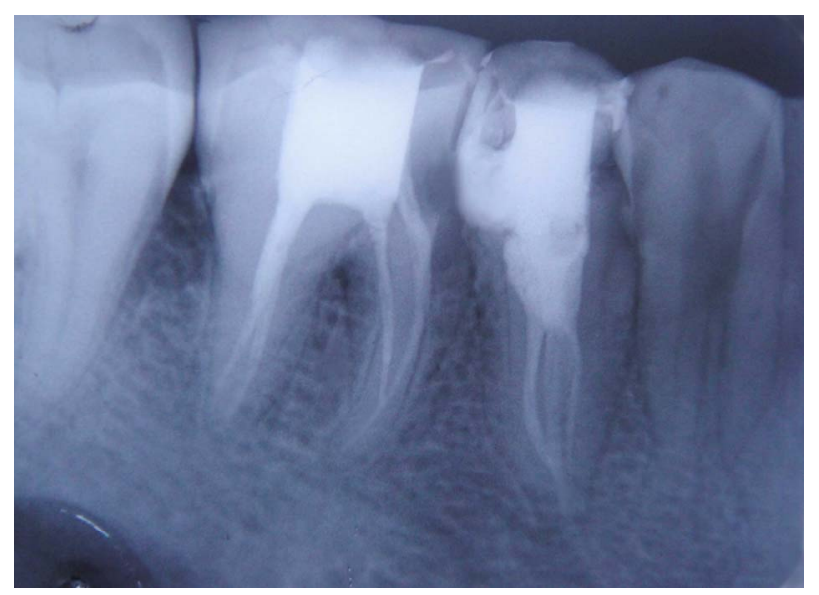

Figure 8. Obturated canals.

canal anatomy of mandibular first molar [4] and second premolar can be aberrant. Luciane F. da Costa et al. (1996) [5] reported in their studies that 5.2\% of mandibular first molar have third root and $21.1 \%$ had four canals. Baugh D. et al. (2004) reported the incident rate of $1 \%$ to $15 \%$ of third canal in the mesial root of mandibular molars [6].

The roots and canals of mandibular permanent first molar have several typical anatomical features as well as great numbers of anomalies. The presence of four canals is relatively frequent [7] but the presence of two distal roots is uncommon [8] and bilateral presence of three rooted mandibular molar is a rare case. Third root anomalies may develop during tooth bud morphodifferentiation as a result of a developmental aberration of both ectoderm and mesoderm [9]. This additional root that can be found disto lingually was first mentioned in literature by De Moore et al. [10] was called "radix entomolaris”.

The morphology of the root and canals of the mandibular second premolar can be complex and variable and is considered to be the most difficult teeth for endo- dontic treatment [11] which is evident with the presence of multiple root canals, apical deltas and lateral canals. $\mathrm{R}$ prakash et al. (2008) in thier survey reported a high incidence of about $1.33 \%$ of two roots \& half of the population showed bilateral presence of two roots in mandibular second premolars [12]. We found taurodontism bilaterally in the mandibular second premolars. The second premolar of the lower left quadrant was affected where as on the lower right quadrant the second premolar was similarly involved. Occurrence of taurodontism in premolars has not been frequently reported in literature. Due to the presence of taurodontism locating the canal orifice was very difficult tasks as the canals were apically positioned. Access cavity also plays a major role in detecting extra canal. Small access cavity results in reduced visualization. This fact is evident in the present case. Initially three canals were located. Access cavity was extended mesially to enhance the visualization of the extra root canal orifice. The advantage of using a microscope is better visualization of the pulp chamber floor and walls that prevent the inadvertent missing orifice. The use of Denta Scan also helped us in determining the root canal configuration and curvature.

\section{CONCLUSION}

It becomes a challenging task even for the astute clinician to identify the presence of an unusual numbers of roots and their morphology. Thus a thorough knowledge of the pulp space morphology and the use of the latest armamentarium are essential for successful outcome of endodontic treatment. Thus unusual pathways may result in frustration for some and fascination for others.

\section{REFERENCES}

[1] Mehrdad, L., Sepideh, V., Vahid, Z., Fatimi, A., Vahab, S. and Bahram, R. (2008) A mandibular second premolar with three canal and atypical orifices. Journal of Oral Science, 3, 363-366.

[2] Jafarzadeh, H., Azarpazhooh, A. and Mayhall, J.T. (2008) Taurodontism: A review of the condition and endodontic treatment challenges. International Endodontic Journal, 41, 375-388. doi:10.1111/j.1365-2591.2008.01388.x

[3] Maniglia-Ferreira, C., De Almeida-Gomes, F., De Sousa, B.C., Dos, C.C., Santos, A. and Dos Santos, R.A. (2008) A case of unusual anatomy in second molar with four canals. European Journal of Dentistry, 2, 217-218.

[4] Mohammad, F.R., Saeed, R. and Shahriar, S. (2007) Root canal therapy of mandibular first molar with five root canals: A case report. Iranian Endodontic Journal, 2, 110112.

[5] Da Costa Rochai, L.F., Manoel, D.S.N., Sandra, R.F., Wanderly, F.D. and Pecora, J.D. (1996) External and internal anatomy of mandibular molars. Brazilian Dental Journal, 7, 33-40. 
[6] Bough, D. and Wallace, J. (2004) Middle mesial canal of the mandibular first molar: A case report and literature review. Journal of Endodontic, 3, 185-186. doi:10.1097/00004770-200403000-00015

[7] Gulabivala, K., Aung, T.H. and Alavi, A. (2001) Root canal morphology of burmese mandibular molar. International Endodontic Journal, 34, 359-370. doi:10.1046/j.1365-2591.2001.00399.x

[8] Prabhu, N.T. and Munshi, A.K. (1995) Additional distal root in permanent mandibular first molar report of a case. Quintessence International, 26, 567-569.

[9] Grover, P.S. and Lorton, L. (1985) Gemination and twinning in the permanent dentition. Oral Surgery, Oral Medicine, Oral Pathology, 59, 313-318.

$$
\text { doi:10.1016/0030-4220(85)90173-2 }
$$

[10] De Moore, R.J., Deroose, C.A. and Calberson, F.L. (2004) The radix entomolaris in mandibular first molar: An endodontic challenge. International Endodontic Journal, 37, 789-799. doi:10.1111/j.1365-2591.2004.00870.x

[11] Slowey, R.R. (1979) Root canal anatomy: Road map to successful endodontic. Dental Clinic of North America, 23, 555-573.

[12] Prakash, R., Nandini, S., Suma, Ballal., Soumya, N.K. and Kandaswamy, D. (2008) Two rooted mandibular second premolars: Case report and survey. Indian Journal of Dental Research, 19, 70-73. doi:10.4103/0970-9290.38936 